\title{
Supercritical fluid jet expansions of polar aromatic carboxylic acids using simple derivatization with detection by resonant two-photon ionization*
}

\author{
Ho Ming Pang, Chung Hang Sin and David M. Lubman ${ }^{\dagger}$ \\ Department of Chemistry, The University of Michigan, Ann Arbor, MI 48109, U.S.A.
}

(Received 21 August 1987)

\begin{abstract}
In this work simple derivatization is used as a means of enhancing the solubility of polar aromatic carboxylic acids in supercritical $\mathrm{CO}_{2}$ and $\mathrm{N}_{2} \mathrm{O}$. The supercritical fluid is then expanded from 200 atm and $40^{\circ} \mathrm{C}$ through a pulsed injection orifice into vacuum as a supersonic jet for analysis by laser resonant two-photon ionization spectroscopy in a time-of-flight mass spectrometer. The use of derivatization reduces the polarity of these carboxylic acids and thus greatly enhances their solubility in these fluids. The result is that strong ionization signals from the jet are detected in the mass spectrometer at relatively low temperatures where these molecules, many of which are thermally labile, will not decompose. The laser ionization method allows soft ionization of these compounds where the molecular ion is generally the base peak and a characteristic fragment due to simple $C_{\alpha}-C_{\beta}$ cleavage is often observed. By monitoring the molecular ion as a function of wavelength a cold laser ionization spectrum with sharp spectral features can be obtained in these supersonic expansions from high pressure supercritical fluids thus demonstrating that optical selectivity is still retained even after derivatization.
\end{abstract}

\section{INTRODUCTION}

THE USE of hyperdense gases also known as supercritical fluids is of current interest as a means of volatilizing nonvolatile and thermally labile molecules into a mass spectrometer [1-4]. The dissolving properties of these fluids have been demonstrated in the past for polynuclear aromatic hydrocarbons (PNAH) that require high temperature $\left(>250^{\circ} \mathrm{C}\right)$ for vaporization and for thermally labile pesticides and even several small biological molecules [1-12]. Although direct liquid introduction methods could also be used for introduction of nonvolatiles into vacuum the much higher volatility of most gases used in supercritical fluid injection (SFI) provides a significant advantage in that the supercritical fluid immediately converts into a gaseous beam of molecules after introduction into the vacuum. Thus, supercritical fluids have the potential to serve as a method of introducing supersonic expansions into a mass spectrometer $[1,4,13]$ for selective spectroscopic analysis. SFI generally utilizes expansion gases with a low enough number of internal modes so that significant cooling of the dissolved materials can be achieved during the molecular beam expansion.

The ultracooling effect obtained by seeding a large molecule in a supersonic jet expansions as in the supercritical fluid expansion described above has been probed using selective laser techniques by FuKuOKa et al. [14] using laser induced fluorescence and by our laboratory using resonant two photon ionization, R2PI, spectroscopy $[4,16]$. In this expansion the internal modes of the seed molecules are cooled due to two-body collisions in which the internal energy of the large polyatomics is transferred to the translational energy of the carrier gas [15]. The result is the appearance of sharp rovibronic lines $(\sim 0.2 \AA)$ which can be probed using pulsed frequency doubled dye lasers in the near ultraviolet region of the spectrum. These lasers have a sufficiently narrow bandwidth $(\sim 0.1 \AA)$ capable of resolving this structure for obtaining spectroscopic selectivity for identification. Thus laser induced resonant two-photon ionization spectroscopy in conjunction with supersonic expansions can be used as a selective ionization source in a mass spectrometer. In our previous work this method was performed using supercritical fluid expansions at relatively low temperature $\left(35-40^{\circ} \mathrm{C}\right)$ in order to volatilize PNAH's and other nonvolatiles with melting points as high as

*An Invited Paper at the XXV CSI, Toronto, Canada.

${ }^{\dagger}$ Author to whom correspondence should be addressed. 
$250-300^{\circ} \mathrm{C}$ for detection and spectroscopic analysis in a time-of-flight mass spectrometer (TOFMS).

Most of the studies of solubilities of materials in supercritical fluids to date have been for relatively nonpolar substances in non-polar or only slightly polar solvents such as $\mathrm{CO}_{2}$ and $\mathrm{N}_{2} \mathrm{O}$. Only very limited work has been performed in highly polar solvents such as $\mathrm{NH}_{3}$ [5] for enhancing the solubility of polar biological molecules. As an alternative we suggest the use of simple derivatization [10] as a means of injecting clinically important biological molecules using supercritical fluids into supersonic beams. By simple modification of the original molecule the polarity can be reduced so that it can be readily dissolved into the standard $\mathrm{CO}_{2}$ or $\mathrm{N}_{2} \mathrm{O}$ fluids without loss of the basic spectroscopic features. This method should greatly enhance the solubility of important molecules for analysis by this method without requiring the use of highly toxic and dangerous polar solvents such as $\mathrm{NH}_{3}$ or of fluids such as methanol which require over $200^{\circ} \mathrm{C}$ to reach supercritical fluid conditions and would result in decomposition of these labile molecules. Although other solvents could conceivably be used, derivatization allows the use of $\mathrm{CO}_{2}$ and $\mathrm{N}_{2} \mathrm{O}$ fluids which provide excellent cooling of these derivatized materials in a pulsed expansion as demonstrated in this work using R2PI spectroscopy in a TOFMS.

\section{ExPerimental Section}

The apparatus for supercritical fluid injection into the supersonic beam time of flight mass spectrometer (TOFMS) has been described in detail elsewhere $[4,16]$. It consists of a differentially pumped system with a TOF mass spectrometer sitting vertically on the top of the ionization chamber. The molecular beam is introduced through a hyperpressure pulsed nozzle, which has been described in an earlier publication [16]. A liquid nitrogen cooled partition plate with a skimmer separates the ionization chamber from the first chamber. The laser beam enters the ionization chamber through a quartz window and R2PI is produced in the acceleration region of the TOFMS. A $150 \mu \mathrm{m}$ orifice is used in the nozzle which results in a pressure of no higher than $2 \times 10^{-5}$ torr in the TOF chamber when the nozzle is operated at $10 \mathrm{~Hz}$ with pulse width of about $600-700 \mu$ s. Six liquid $\mathrm{N}_{2}$ cryobuckets are used to pump efficiently the condensible $\mathrm{CO}_{2}$ and $\mathrm{N}_{2} \mathrm{O}$ carrier gases. The supercritical fluid is provided by two Varian 8500 syringe pumps which are operated in series so that the fluid can be delivered to the molecular beam continuously. This illustrates the importance of pulsed injection since the reservoir would last for only a very short time with a $150 \mu \mathrm{m}$ orifice in a continuous flow. The supercritical fluid is flowed over the material in the reservoir and into the pulsed valve for injection into the mass spectrometer. The sample reservoir is heated to $\sim 40-50^{\circ} \mathrm{C}$ and the pulsed nozzle is generally heated $10^{\circ} \mathrm{C}$ higher to prevent clogging.

The hyperpressure pulsed valve used in this work has been modified over that used in previous work. The valve now can operate at up to $200^{\circ} \mathrm{C}$ by replacing the $\mathrm{O}$-ring seal between the body and face plate with a metal-to-metal gasket seal. The new valve has been machined so that a 1.90 in. (o.d.) standard OFHC $^{\mathrm{R}}$ copper gasket can be used as a seal between two sharp metal teeth as copied from the standard Varian type flange. The faceplate was also made thicker $(\sim 0.4 \mathrm{in}$.) and is now held by $121 / 4-20$ cap screws in order to better withstand the high pressure in the valve. Also, the front disk that holds the aperture was made thicker to prevent bending. In our previous design the faceplate could distort and bend due to the pressure over a period of time.

The laser system is a Quanta-Ray DCR2A Nd:YAG pumped dye laser (PDL-2A) system, in which $266 \mathrm{~nm}$ ultraviolet light is generated as the fourth harmonic of the $1.06 \mu \mathrm{m}$ fundamental. In addition, a WEX wavelength extension device is used to frequency double dye laser radiation in KDP in order to obtain u.v.-visible radiation. The light is collimated with a positive/negative quartz lens telescope to a $\sim 2-\mathrm{mm}$ beam. The ions produced by laser R2PI in the supersonic jet were mass analyzed using a TOFMS. The signals were averaged 100 times by a LeCroy 9400 digital oscilloscope. The wavelength spectrum was obtained by using a gated integrator to monitor the molecular ion of the species of interest as a function of laser wavelength.

The compounds studied herein all contain a polar $-\mathrm{COOH}$ group and were obtained from either Aldrich or Sigma Chemicals. In order to increase the solubility of these compounds an alkylation of the form shown in (I) was performed [17] following the procedure of FrICK et al::

$\mathrm{MeOH} / \mathrm{CH}_{3} \mathrm{COCl}(\mathrm{v} / \mathrm{v}$ 4:1)

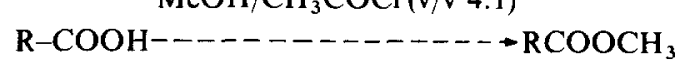

$50^{\circ} \mathrm{C} \mathrm{N}_{2}$ stream 
The derivatized product is dissolved in a small amount of methanol and placed in the experimental reservoir.

\section{RESULTS and Discussion}

Table 1 lists the compounds studied by R2PI injected into the TOFMS using supercritical fluid injection. The first three columns show the original carboxylic acid, its structure and molecular weight. Most of these compounds cannot be detected by R2PI from supercritical fluid injection with any significant signal above the noise level at $50^{\circ} \mathrm{C}$ and $250 \mathrm{~atm}$ reservoir pressure of $\mathrm{CO}_{2}$ or $\mathrm{N}_{2} \mathrm{O}$. This is due to the low solvation power of $\mathrm{CO}_{2}$ and $\mathrm{N}_{2} \mathrm{O}$ for these compounds with very polar functional groups. The fourth column shows the ion masses observed in the mass spectra. The last column lists the mass differences between the molecular ions of the derivatives in the mass spectra and the original acids.

Table 1. R2PI induced mass spectral data for derivatized carboxylic acids at $266 \mathrm{~nm}$

\begin{tabular}{|c|c|c|c|c|}
\hline Compound & Structure & M.W. & $\underline{M} / \mathbf{Z}$ & $\partial \mathbf{M}^{*}$ \\
\hline $\begin{array}{l}\text { 1. 5-methoxy } \\
\text { indole-3-acetic acid }\end{array}$ & & 205 & $\begin{array}{l}219 \\
160\end{array}$ & 14 \\
\hline 2. indole-3-acetic acid & & 175 & $\begin{array}{l}189 \\
130\end{array}$ & 14 \\
\hline 3. phenyl acetic acid & & 136 & $\begin{array}{r}150 \\
91\end{array}$ & 14 \\
\hline $\begin{array}{l}\text { 4. p-hydroxy phenyl } \\
\text { acetic acid }\end{array}$ & & 152 & $\begin{array}{l}166 \\
107\end{array}$ & 14 \\
\hline 5. homovanillic acid & & 182 & $\begin{array}{l}196 \\
137\end{array}$ & 14 \\
\hline $\begin{array}{l}\text { 6. p-hydroxy phenyl } \\
\text { lactic acid }\end{array}$ & & 182 & $\begin{array}{l}196 \\
107\end{array}$ & 14 \\
\hline $\begin{array}{l}\text { 7. 4-hydroxy-3-methoxy } \\
\text { phenyl lactic acid }\end{array}$ & & 212 & $\begin{array}{l}226 \\
137\end{array}$ & 14 \\
\hline $\begin{array}{l}\text { 8. 3-(4-hydroxy phenyl) } \\
\text { propionic acid }\end{array}$ & & 166 & $\begin{array}{l}180 \\
107\end{array}$ & 14 \\
\hline 9. p-anisic acid & & 152 & $\begin{array}{l}166 \\
135\end{array}$ & 14 \\
\hline 10. m-anisic acid & & 152 & $\begin{array}{l}166 \\
135\end{array}$ & 14 \\
\hline $\begin{array}{l}\text { 11. 3-hydroxy-4-methoxy } \\
\text { mandelic acid }\end{array}$ & & 198 & $\begin{array}{l}226 \\
167\end{array}$ & 28 \\
\hline $\begin{array}{l}\text { 12. 4-hydroxy-3-methoxy } \\
\text { mandelic acid }\end{array}$ & & 198 & $\begin{array}{l}226 \\
167 \\
151\end{array}$ & 28 \\
\hline
\end{tabular}

* $\partial M=$ mass difference between the molecular ion and the original acid 
Figure 1 shows the laser R2PI mass spectra of several of the derivatives of the compounds listed in Table 1. Many of these compounds are important metabolities of tyrosine or catecholamine metabolism in the body. In these experiments the derivatives were expanded from supercritical $\mathrm{CO}_{2}$ or $\mathrm{N}_{2} \mathrm{O}$ at 200 atm backpressure and $\sim 45^{\circ} \mathrm{C}$ and ionized using R2PI at $266 \mathrm{~nm}$. In each case the molecular ion peaks indicated that a $-\mathrm{CH}_{3}$ group had been added to the carboxylic acid group. Even though the molecular ion is the dominant product of R2PI at modest laser energy, fragmentation peaks are produced here even at the threshold laser energy needed for ionization. This fragmentation generally involves simple cleavage of the $\mathrm{C}_{\alpha}-\mathrm{C}_{\beta}$ bond in the alkyl side chain. Most of these compounds formed a similar stable fragment, i.e. a substituted benzyl cation. In the case of the derivatives of the anisic acid isomers (in which $-\mathrm{COOH}$ is attached directly to the aromatic ring) both the molecular ion

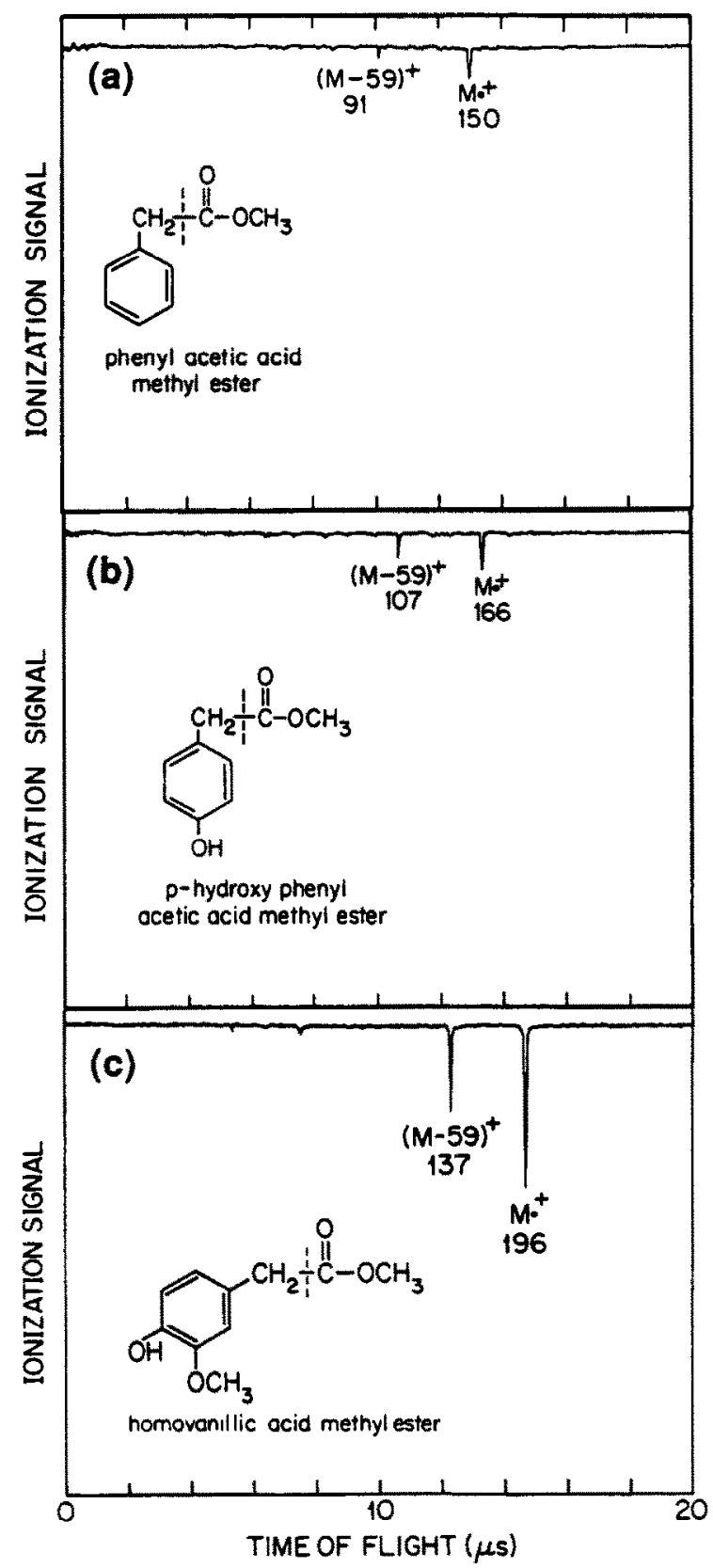

Fig. 1. Time-of-flight mass spectra (a) phenyl acetic acid methyl ester expanded from a jet at 250 atm back pressure of $\mathrm{N}_{2} \mathrm{O}$ at $50^{\circ} \mathrm{C}$; (b) p-hydroxy phenyl acetıc acid methyl ester and (c) homovanillic acid methyl ester expanded from a jet at 200 atm back pressure of $\mathrm{CO}_{2}$ at $40^{\circ} \mathrm{C}$. 
and a M-31 fragment appear in the mass spectra. The fragment arises from loss of a methoxy group from the derivatized $\mathrm{COOCH}_{3}$ substituent instead of the whole ester group as in the other cases. The underivatized form of all these compounds in Table 1 could not be detected under similar supercritical fluid expansion conditions in these experiments. However, using this combination of supercritical fluids and derivatization, these molecules can be injected into supersonic expansions at relatively low temperature.

The situation is slightly different in the case of 3-methoxy-4-hydroxy mandelic acid methyl ester and its isomer 4-methoxy-3-hydroxy mandelic acid methyl ester (Table 1) where the molecular ion produced by R2PI increased by 28 mass units instead of the 14 observed in the other cases, as compared to the original acids. This means that two- $\mathrm{CH}_{3}$ groups were added during derivatization. When one considers the structures of these two isomers there are two other hydroxy groups that might be alkylated in addition to the - $\mathrm{COOH}$ group. However, our other results (Table 1), indicate that hydroxy groups directly attached to the benzene ring are not readily derivatized. We thus conclude that the hydroxy group on the side chain has been converted to a methoxy group during the derivatization process. In these compounds the fragments at $m / z=167$ resulted from $C_{\alpha}-C_{\beta}$ cleavage in the side chain that formed a substituted benzyl cation as in the previous examples. In the case of 4-methoxy-3hydroxymandelic acid methyl ester, the peak at $m / z=212$ seems due to the incomplete reaction in which the hydroxy group on the $\beta$-carbon of the side chain remained unchanged. The fragment of 153 (i.e. 212-59) serves as evidence of this incomplete reaction.

The key question is whether spectroscopic wavelength selectivity is maintained in these expansions after derivatization. In Fig. $2 b$ is the R2PI induced mass spectrum $(\lambda=266 \mathrm{~nm})$ of indole-3-acetic acid methyl ester expanded from supercritical fluid $\mathrm{N}_{2} \mathrm{O}$ at 200 atm and $40^{\circ} \mathrm{C}$. The base peak is the molecular ion, $\mathrm{M}^{+}(\mathrm{m} / z=219 \mu)$. If the gate of a gated integrator monitors the $\mathrm{M}^{+}$peak as a function of wavelength, a mass-selected wavelength spectrum is observed as shown in Fig. 2a. The wavelength spectrum can be used as a unique fingerprint with which to identify indole-3-acetic acid methyl ester from other compounds which have the same molecular weight and a similar fragmentation pattern.

Indole-3-acetic acid and its ethyl ester are important plant hormones. However, they were chosen for study specifically because some spectrosocpic information is available on these and related compounds and they absorb in a region easily accessible to our tunable dye laser. It should be noted that BeHRsun et al. [18] were able to obtain a laser induced fluorescence spectrum of indole-3-acetic acid at $120-150^{\circ} \mathrm{C}$ and 550 torr of He carrier with an origin band at $293.74 \mathrm{~nm}$. We were unable to locate this band for the methyl ester or the original compound using R2PI by heating the sample into the beam. LEvy et al. have correctly obtained the indole acetic acid origin at $285.40 \mathrm{~nm}$ and have observed multiple geometric conformers of the origin band [19]. The original spectrum reported by BEHRSONet al. may very well have been due to decomposition or rearrangement products thus demonstrating the utility of using a lower temperature provided by derivatization with supercritical fluid injection. It should be noted that even the methyl ester cannot be observed using $1 \mathrm{~atm} \mathrm{Ar}$ carrier gas expansions at a temperature lower than $\sim 70-80^{\circ} \mathrm{C}$. The derivatization process changes the absorption spectrum of the original molecule and also the ionization potential. Since the attached group is away from the benzene ring one would not expect the basic $\pi-\pi^{*}$ transition to be altered greatly. However, the ability to obtain sharp spectral features cannot be assumed a priori since the addition of the derivatized group may open up rotational degrees of freedom that prevent full cooling $[20,21]$. Nevertheless, we do observe structured features in this region of the indole-3-acetic methyl ester spectrum which is comparable to that observed by LevY et al. [19] in the case of $N$-acetyl-tryptophanethyl ester in the same spectral region at $160^{\circ} \mathrm{C}$. The spectral region between $279-284 \mathrm{~nm}$ was chosen for examination since it represents the peak of a strong laser dye output (Rhodamine 590 and 575) which can be used to obtain excellent signal to noise. The spectrum appears structured but not highly resolved in the region which appears to consist of a large number of combination bands which are multiplied by the many structural conformers of these indole compounds. The origin bands of these related indole analogs are located in the region between 285-287 nm and have been shown to consist of multiple peaks corresponding to the origin transitions of several different geometrical conformers [19]. The spectra are thus more 

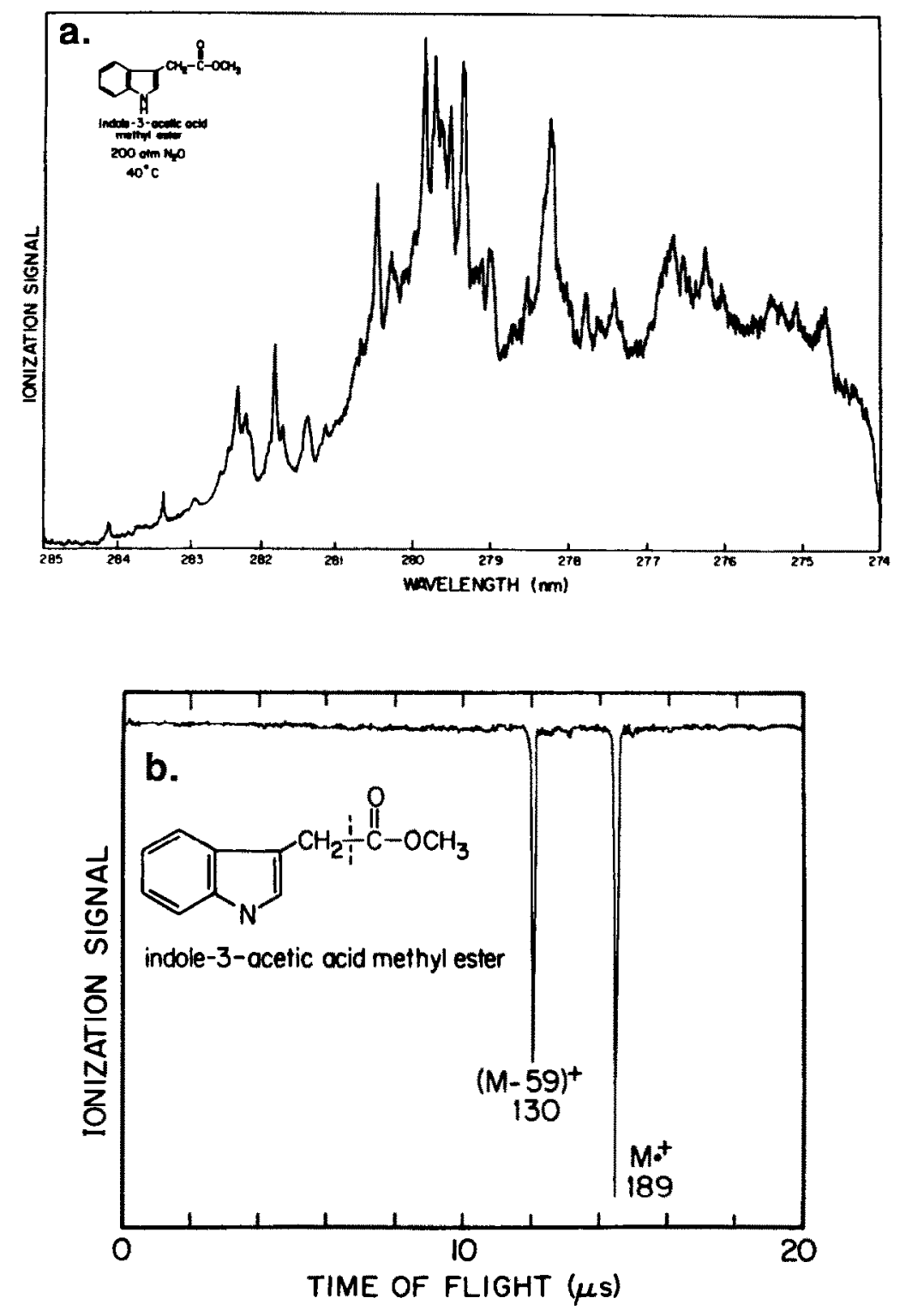

Fig. 2. (a) R2PI spectrum of indole-3-acetic acid methyl ester. (b) Time-of-flight mass spectrum of indole-3-acetic acid methyl ester at $\lambda=266 \mathrm{~nm}$. Both (a) and (b) are expansions from a supersonic jet of supercritical fiuid $\mathrm{N}_{2} \mathrm{O}$ at a back pressure of 200 atm and $40^{\circ} \mathrm{C}$.

congested than the relatively rigid molecules often studied by this technique. These conformers can generally be resolved under the low laser intensity conditions of laser induced fluorescence but become difficult to resolve well at the higher laser energies needed to produce efficient R2PI in our own studies.

Thus, simple derivatization which converts a polar $\mathbf{R}-\mathrm{COOH}$ group into a less polar $\mathrm{R}-\mathrm{COOCH}_{3}$ group can greatly enhance the solubility of these compounds in supercritical fluids such as $\mathrm{CO}_{2}$ and $\mathrm{N}_{2} \mathrm{O}$ for supersonic jet injection into mass spectrometry. This technique allows one to use these nonpolar or slightly polar solvents that are relatively nontoxic and easy to handle for these supercritical fluid experiments. Although more polar solvents can be used, in practice they are generally quite toxic and corrosive and may not be suitable for obtaining cooling in supersonic jets. Using a tunable u.v. laser source, R2PI spectra of the derivatized compounds expanded from supercritical fluids can be obtained with cold structured spectral features for unique identification. 
Acknowledgements-We would like to gratefully acknowledge support of this work by the donors of the Petroleum Research Fund, administered by the American Chemical Society under Grant PRF No. 18925-AC5 and by the National Science Foundation under NSF Grant CHE-8419383 and Grant DMR 8418095 for acquisition of the Chemistry and Materials Science Laser Spectroscopy Laboratory. DAvid M. LUbMAN is a Sloan Research Foundation Fellow. We would like to acknowledge JeNs ZORN for helpful suggestions during the course of this work.

\section{REFERENCES}

[1] L. G. Randall and A. L. Wahrhaftig, Anal. Chem. 50, 1703 (1978).

[2] R. D. Smith, W. D. Felix, J. C. Fjeldsted and M. L. Lee, Anal. Chem. 54, 1883 (1982).

[3] R. D. Smith and H. R. Udseth, Anal. Chem. 55, 2266 (1983).

[4] C. H. Sin, H. M. Pang, D. M. Lubman and J. Zorn, Anal. Chem. 58, 487 (1986).

[5] J. C. Giddings, M. N. Myers, L. McLaren and R. A. Keller, Science 162, 67 (1968).

[6] J. C. Giddings, M. N. Myers and J. W. King, J. Chromat. Sci. 7, 276 (1969).

[7] R. E. Jentoft and T. H. Gouw, Anal. Chem. 44, 681 (1972).

[8] R. E. Jentoft and T. H. Gouw, Anal. Chem. 48, 2195 (1976).

[9] J. C. Fjelsted and M. L. Lee, Anal. Chem. 56, 619A (1984).

[10] T. L. Chester and D. P. Innis, J. High Res. Chromat. 9, 177 (1986).

[11] D. W. Later, B. E. Richter, D. E. Knowles and M. R. Andersen, J. Chromat. Sci. 24, 249 (1986).

[12] E. Stahl, W. Schilz, E. Schütz and E. Willing, Agnew Chem. Int. Ed. Engng 17, 731 (1978).

[13] L. G. Randall and A. L. Wahrhaftig, Rev. Sci. Instrum. 52, 1283 (1981).

[14] H. Fukuoka, T. Imasaka and N. Ishibashi, Anal. Chem. 58, 375 (1986).

[15] R. E. Smalley, L. Wharton and D. H. Levy, Acc. Chem. Res. 10, 139 (1977).

[16] H. M. Pang, C. H. Sin, D. M. Lubman and J. Zorn, Anal. Chem. 58, 1581 (1986).

[17] W. Frick, G. D. Daves, Jr, D. F. Barofsky, E. Barofsky, G. H. Fisher, D. Chang and K. Folkers, Biomed. Mass Spectrom. 4(3), 152 (1977).

[18] R. Behrson, U. Even and J. Jortner, J. Chem. Phys, 80, 1050 (1984).

[19] Y. D. Park, T. R. Rizzo, L. A. Peteanu and D. H. Levy, J. Chem. Phys. 84, 6539 (1986).

[20] R. Tembreull and D. M. Lubman, Appl. Spec. 41, 201 (1987).

[21] J. B. Hopkins, D. E. Powers and R. E. Smalley, J. Chem. Phys. 72, 5039 (1980). 